\title{
Una tradición constructiva del Norte Chico
}

Rocío Blaitt Profesora, Escuela de Arquitectura, Universidad de La Serena.

Buena parte de la arquitectura rural tiene un origen material en el territorio donde se emplaza. La hacienda El Tangue es ejemplo de esta relación: debido a su aislamiento, sus viviendas y galpones aprovechan los suelos arcillosos y la totora que crece en los humedales cercanos como materiales de construcción eficientes y de bajo costo.
A good part of rural architecture contains material sourced from the territory where it is emplaced. El Tanque Hacienda is an example of this relationship: due to its isolation, its homes and barns for which the clay soil and the bulrush that grows in the wetlands nearby were used as efficient and low-cost construction materials.

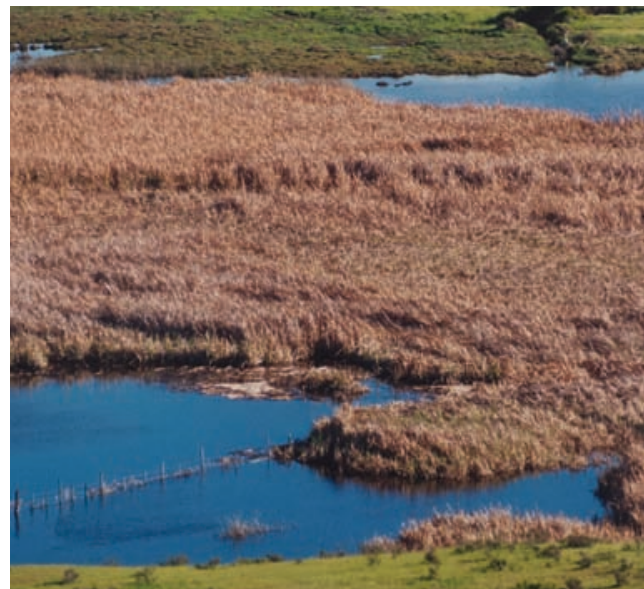

01

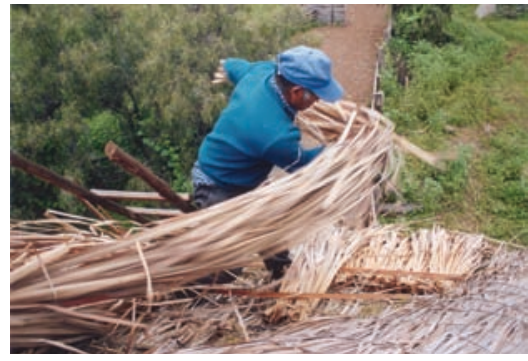

03

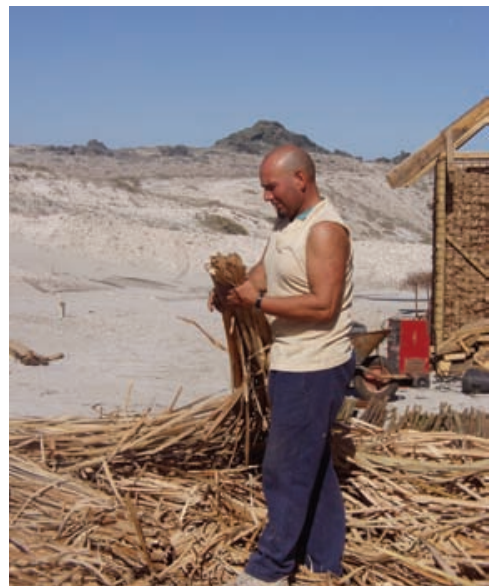

02

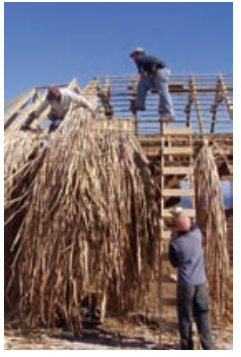

04

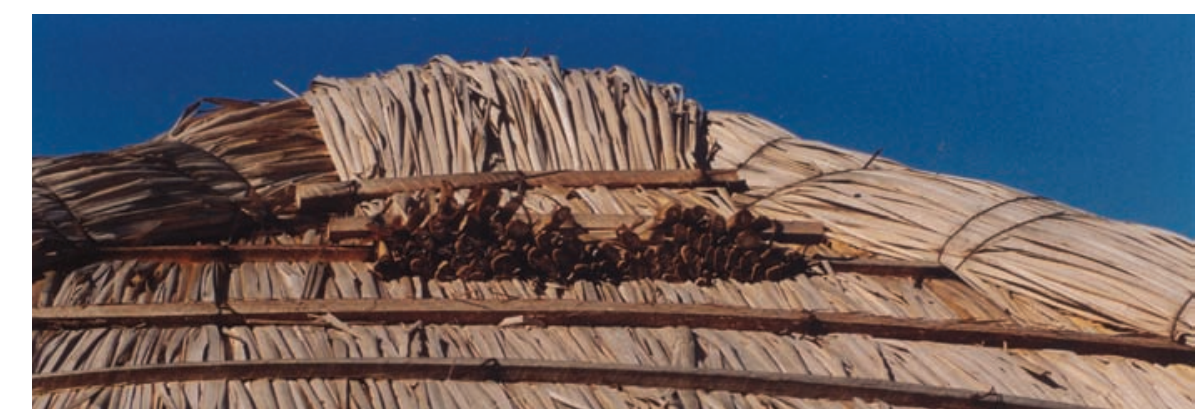

07

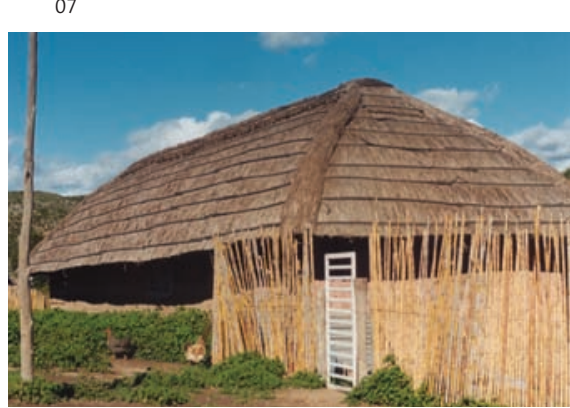

09

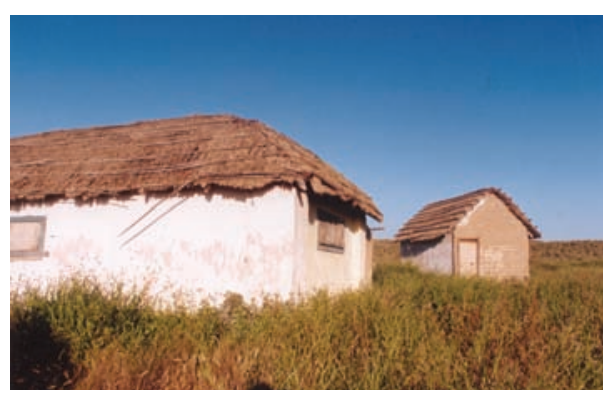

10

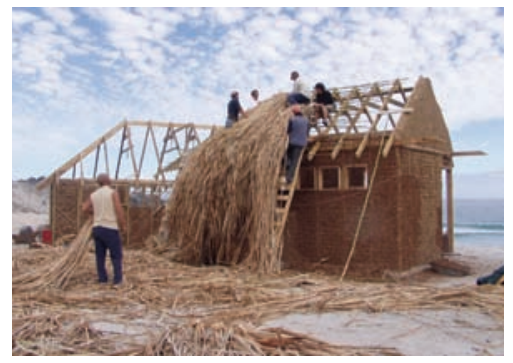

05

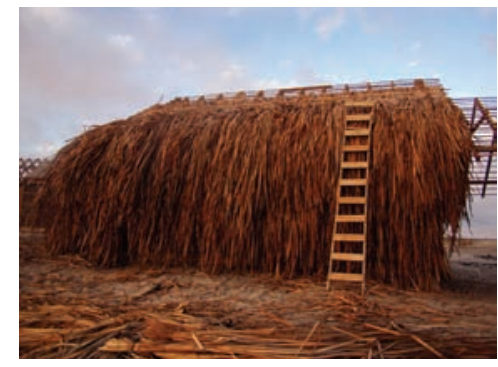

06
01 Totoral en Tongoy Alto, región de Coquimbo

02 Armado de un hachón de totora seca

03 - 06 Proceso de colocación de las gavillas y techado

Encuentro de aguas con cumbrera

08 Cielo interior, techo de totor

09 - 10. Viviendas de la hacienda El Tangue en barro y techo de totora

11 Galpón de esquila, hacienda El Tangue, arquitecto Marcelo Bachelet, c. 1950

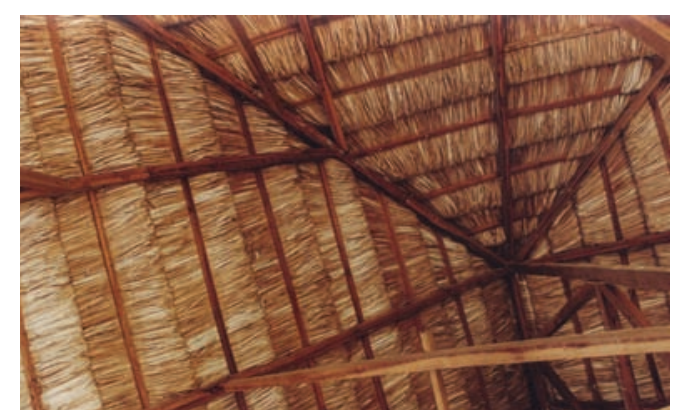

08

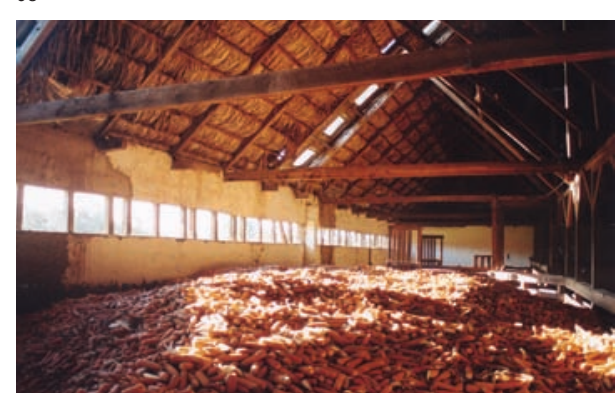

11 
A través de la evolución de culturas y civilizaciones va cambiando la percepción del tiempo y con ello el modo de vivir, entendiendo el tiempo más que como una simple sucesión cronológica, sino como una manera de vivir el momento presente. De esta forma, cuando aparece la agricultura, surge el concepto de futuro y la programación de las cosechas. Asimismo, con la llegada de los españoles a América surge otro tiempo, asociado a un nuevo modo de desplazamiento, el tiempo del caballo, implicando de esta manera toda una nueva forma de vivir y percibir el mundo.

Hace no más de 50 años, el mundo rural del Norte Chico de Chile también tenía otro tiempo, otro ritmo de vida. Un tiempo en que las distancias eran mucho más inabarcables. Un ritmo sin carreteras doble vía, ni luz eléctrica. Era un tiempo de sentarse frente al paisaje, simplemente a observar cómo pasaba el día por delante de los ojos.

Un sistema constructivo como el que aquí se describe es parte de un modo de habitar el mundo, una manera de percibir el territorio en el cual se habita como una extensión de la vivienda. Sistemas constructivos tradicionales como este, inevitablemente desaparecen si no existe un modo de vivir que lo sustente.

El BARRO Y LA TOTORA: CONSTRUYENDO EN EL MUNDO RURAL / En la hacienda El Tangue, ubicada hacia el sur del balneario de Tongoy, en la región de Coquimbo, se levantaron hace casi 70 años cerca de 60 viviendas de muros de tierra cruda y cubierta de vegetal. Estas fueron construidas para renovar las casas de inquilinos que vivían en condiciones deplorables. El modelo de vivienda empleado es una fusión entre la tradición constructiva de la zona y la influencia de la administración galesa que tenía la hacienda en ese momento. Como consecuencia de la Segunda Guerra Mundial, El Tangue tuvo que autoabastecerse en cuanto a materiales de construcción y sólo se utilizaron materiales del lugar: madera, brea, totora y tierra. Con estos materiales que ofrecía el entorno se crearon espacios habitables de carácter singular. Las construcciones surgen en el paisaje desde el territorio en que se emplazan transformando, literalmente, la naturaleza en una vivienda, mimetizándose y complementándose con el medio ambiente.

Hoy quedan cerca de 30 construcciones de esas características. A pesar que la totora continúa creciendo en los humedales de la hacienda y la tierra posee, invariablemente, las mismas propiedades para construir con barro, no se continúa construyendo con ese sistema. Todavía existen algunos habitantes que conocen los sistemas constructivos tradicionales, pero sólo se encargan de reparar las cubiertas y muros que perduran en el tiempo.

La construcción con barro es parte de un conjunto de factores que componían un mundo rural a la antigua, partiendo desde la elección de la tierra y su justa composición hasta usarla en una construcción. A pesar que existen varios libros con diversos ensayos de laboratorio, nadie puede hacer un mejor diagnóstico que el ojo del campesino experimentado. Es esa medida justa entre arena, arcilla y limo la que produce una consistencia que puede percibirse en la tierra mojada con la sensibilidad de una mano entendida. En la combinación del barro con la paja, tampoco hay medidas definidas. Existe una proporción y un modo tradicional de preparación, como el caminar de un caballo por sobre la mezcla húmeda para amalgamar los dos elementos. Para conseguir una buena alianza es necesario un tiempo de reposo de al menos 10 días; sólo después de esta espera se empieza a construir. De esa manera, por generaciones, los lugareños han convertido la misma tierra que pisan en un material constructivo con el que se pueden levantar muros para viviendas de propiedades térmicas indiscutibles.

El techado con totora ${ }^{1}$ requiere quizás más tiempo y paciencia que el barro. De hecho, hay que partir esperando. Sólo en los meses de verano se puede cortar buena totora: verde y larga, porque en el verano es más bajo el nivel de las aguas en los humedales, y así es más fácil segar la totora. Luego hay que esperar nuevamente un par de meses: el tiempo de secado. Con la totora ya seca, recién se puede comenzar a engavillar. La gavilla es una medida dada por el cuerpo: se refiere a la cantidad de totora que cabe en una mano y se usa como el primer módulo en el techado. Las gavillas se ordenan y amarran para armar los hachones, que tampoco son una medida abstracta, si no que corresponden a un atado de gavillas suficiente para que un hombre sea capaz de sostenerlo y subirlo hacia la estructura del techo.

También es importante el momento del día en que se trabaja. Preferentemente, la instalación debe realizarse sólo en las mañanas y comenzando desde bien temprano. Así la totora todavía conservará la humedad de la noche, y de esta manera no se resquebrajará al manipularla. Esos y otros detalles se van traspasando de generación en generación, en la medida que la técnica se siga aplicando.

La instalación de las gavillas es una labor minuciosa y puede resultar muy lenta comparada a otros sistemas. Una a una, se ubican por corridas, de abajo hacia arriba, traslapando las capas. Se construye así un grueso manto vegetal de propiedad aislante sobresaliente. Bajo este manto se genera un interior que, en conjunto con los muros de barro, genera una calidez espacial extraordinaria.

Como cualquier otro elemento que compone el paisaje natural, ese tipo de construcciones acusan noblemente el paso de los años. El viento y la lluvia van horadando los muros de tierra, y la cubierta de totora se va tornando gris por efecto del sol. Los campesinos restauran las grietas en los muros con nuevas capas de barro, tomando la misma tierra que la lluvia ha lavado en inviernos demasiado crudos, reciclándola.

La cubierta, que se adelgaza año a año, vulnerable al implacable sol del norte, necesita restauración cada 15 a 20 años. La totora envejecida del manto superior permanece y simplemente se agrega una nueva capa encima, renovando el techo. De esta manera las diferentes capas de totora, con varias tonalidades, evidencian el paso del tiempo en las construcciones, como los anillos en un árbol.

Si las viviendas no se reparan y se abandonan dejando pasar el tiempo, el proceso de deterioro continúa hasta que naturalmente vuelven a su origen: a la tierra. Se biodegradan, como cualquier ser vivo. Una construcción que nace y muere en su medio ambiente natural, se potencia y completa con el lugar en el que se emplaza. No es en sí misma, si no con el todo. Pronto no quedarán vestigios y todo volverá a la tierra. ARQ 